\title{
Symbiosis: twenty years after - how things have changed an introduction to the proceedings of the seventh International Symbiosis Congress
}

\author{
David C. Smith
}

Received: 10 November 2012 / Accepted: 11 November 2012 / Published online: 22 November 2012

(C) Springer Science+Business Media Dordrecht 2012

It is 20 years since the proceedings of the first International Congress on Symbiosis held in Jerusalem in 1991 was published. Before that time, in the entire 20th century, there had previously been only four international conferences on the subject of symbiosis: in 1963, by the Society for General Microbiology; in 1974, by the Society for Experimental Biology; in 1978, by the Royal Society of London; and in 1981, by the New York Academy of Sciences. There was, however, a small conference on symbiosis organised in Tubingen in 1980 by some of those working on intracellular associations. This led to the founding of the Society for Endocytobiology, and the later establishment of the journal Endocytobiology and Cell Research. Before this time, such was the remoteness of symbiosis from central issues in biology that when, in the 1970s, in a lecture to students at Oxford University I explained Lynn Margulis' 1967 theory of the symbiotic origin of mitochondria, I was subsequently admonished by a senior member of my faculty for talking about 'such a silly idea' to students. At that time, there was a general awareness that major groups of organisms - such as land plants, herbivorous insects and mammals - derived significant and sometimes essential benefit from intimate associations with various microorganisms. However, symbiosis was not regarded as an important subject. So how did symbiosis begin to occupy a more central position in biology?

It was the tireless efforts of the distinguished Israeli biologist, Margalith Galun which led to the founding in 1986 of the journal Symbiosis, the first scientific journal solely devoted to the subject in all its aspects. She was also the central figure, 5 years later, in organising the first International Congress on Symbiosis in Jerusalem in 1991, which attracted 250 participants from 27 countries. The

D. C. Smith $(\bowtie)$

Edinburgh, Scotland, UK

e-mail: Smithsymbiosis@aol.com organisation of its programme had the deliberate aim that each session should cover topics or phenomena that different associations have in common such as: nutritional interactions, recognition and specificity, symbiosis and the development of new structures and functions, ecological adaptations, transport mechanisms, etc. This ensured - far more than any of the few preceding conferences - extensive contact and collaboration between those working on different types of symbiosis. A measure of the response to the first International Symbiosis Congress was that the keynote speakers came from Europe, America and Australia as well as from Russia and Eastern Europe. They contributed written versions of their presentations which with other papers resulted in a proceedings volume (Symbiosis volume 14 (13) that ran to 500 pages and is an excellent source for appreciating the level of understanding of symbiotic systems at that date. The first Symbiosis Congress was so successful that a call for another Congress ensued, which was held in 1994 (and at regular intervals ever since), and this led to the foundation a few years later of the International Symbiosis Society. At last, research into the general subject of symbiosis developed a more global momentum.

How things have changed! Just 20 years later! As an example, we can take the title of this 7 th International Symbiosis Society Congress: "The earth as a vast symbiosphere". Twenty years ago, the term 'symbiosphere' was virtually unheard of - and would have been considered meaningless by most biologists. For although scientists, at that time, had begun to recognise that symbiosis was of widespread occurrence, very few considered it to be of the major significance to evolution and to terrestrial ecosystems that is accepted today. Over the past 20 years, the progress of research and the spread of knowledge has proceeded to the extent that the crucial role of symbiosis in the evolution of eukaryotes and in the structure and composition of terrestrial ecosystems is now widely accepted. Without the 
phenomenon of symbiosis, life on earth today would probably be radically very different. Thus, the term 'symbiosphere' correctly reflects the global importance of the topic. The other major change has been the application of molecular biology that has enabled people to understand genetic exchange between hosts and symbionts and to identify the extent of differences between symbionts and free-living forms. Molecular techniques are becoming even more sophisticated and revealing clues to the function of particular symbiotic systems.

The programme for the 7 th congress reveals the diversification of research into topics that might have been considered unachievable 20 years ago, such as horizontal gene transfer and the role of viruses, medical implications of symbiosis, agricultural and industrial enhancement, climate change and environmental impacts. Who would have believed at the first congress that a session on "Symbiont based control of arthropod pests and disease vectors" would be possible? Those involved in the operation of the International Symbiosis Society, the organisation of International Symbiosis Congresses, and the editing of relevant journals deserve much credit for what has happened in the field of symbiosis over the last 20 years.

Editorial Note: D.H.S. Richardson

Professor Sir David Smith, a friend and colleague of Professor Margalith Galun, gave a keynote address and wrote the introductory review entitled "The symbiotic condition" that can be found in the proceedings of first ISS Congress. He led a pioneering research group at the University of Oxford which focused on understanding the nutritional interactions between the lichen symbionts and then extended these studies to coelenterates. With colleagues, he wrote a number of important reviews dealing with the movement of carbohydrates between autotrophs and heterotrophs in parasitic and mutualistic symbioses. He later became professor of Botany at Bristol University, Principal of Edinburgh University and President of Wolfson College Oxford. He was awarded a Gold Medal for Botany by the Linnean Society and served as its President (2000-2003). Professor Sir David Smith is now retired and lives in Edinburgh, Scotland. 